\title{
Anesthetic management of ruptured AVM with inner aneurysm: neurointerventional radiologist and anesthesiologist hand by hand
}

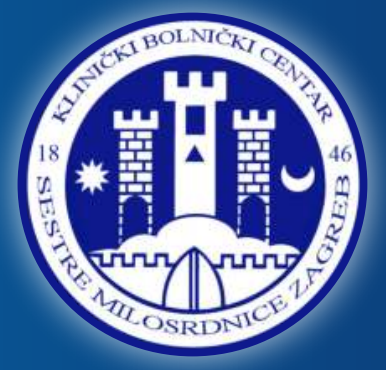

Videc Penavić L', Kalousek V² Čulo B², Horvat A', Krolo Videka H', Gavranović Ž1

University Hospital "Sestre milosrdnice", Dept of Anesthesiology, Critical Care and Pain Management; University of Zagreb, School of Medicine, Zagreb, Croatia

2 University Hospital "Sestre milosrdnice", Dept of of Diagnostic and Interventional Radiology; University of Zagreb, School of Medicine, Zagreb, Croatia

\section{INTRODUCTION}

Embolization of aneurysms, arteriovenous malformations (AVMs) and escalating number of other neurointerventional procedures are best conducted under general anesthesia, which allows patient immobility, blood pressure manipulations and cerebral protection(1). Anesthesiologist prevents and responds to procedural complications and together with neurointerventional radiologist deals with different working environment and specific requirements(2).

\section{CASE REPORT}

A 27-year old female presented with sudden intensive headache and excessive vomiting. Neuroimaging revealed haemorrhage from AVM with intranidal aneurysm. Medical team decided on neurointerventional procedure in general anesthesia. Midazolam, sufentanyl and propofol were used for induction, with iv bolus of esmolol before intubation. Sevofluran, sufentanyl and vecuronium were used for maintenance of anesthesia.

Monitoring of Sp02, EtCO2, arterial blood pressure with arterial line, ECG and urinary output was performed.

Coils were placed using the pressure cooker technique, and embolisation agent was injected intranidaly. Sudden rise in blood pressure occurred at the same time the radiologist noticed the rupture of the intranidal aneurysm. Anesthesia was deepened and mannitol infusion started. The radiologist occluded aneurysm by injecting liquid embolic material. Complete AVM obliteration was achieved.

After waking up, the right hand paresis and sensomotor dysphasia were present. A control CT scan showed ischemic changes in the left ACM irrigation area. Three months later, minor motor dysphasia was present. Six months later, only dysgraphia and acalculia remained.

\section{CONCLUSION}

Anesthesiologist awareness and quick response can be vital in case of emergencies that could happen from the entrance of the patient into the operating room, till his transportation to ICU.

Performing neurointerventional procedures with a permanent anesthesia team in the radiology department proves to be invaluable and rapid and effective communication between anestesiologist and radiologist is essentional for good outcome.

\section{References}
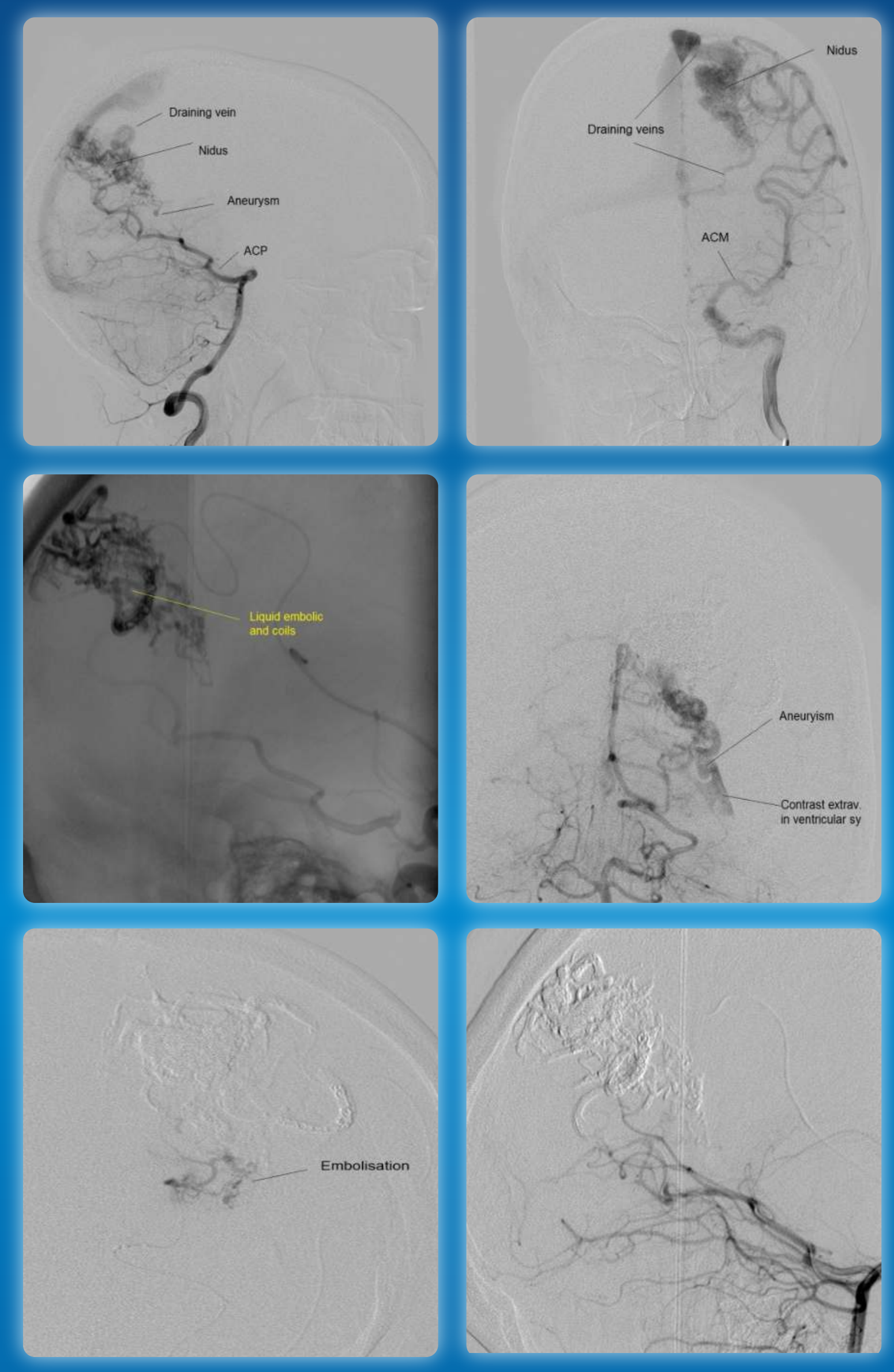

\section{DISCUSSION}

Anesthesiologist confronts a few moments linduction, intubation, extubation, some neurointerventional maneuvers and sudden unexpected procedure-related complications] when there is need for tight intracranial pressure and hemodynamic control. One should be able to respond very quickly to radiologist demands, lowering and raising MAP and ICP, using various different drugs and maneuvers, making optimal conditions for performing the most delicate procedures on cerebral vascular structures. Deliberate hyper or hypotension and management of coagulation are, among others, often part of specific anesthesia dealing with haemorrhagic and occlusive complications(3).

1. Nadjat-Haiem C, Ziv K, Osborn I. Anesthesia for carotid and cerebrovascular procedures in interventional neuroradiology. Int Anesthesiol Clin. 2009;47(2):29-43

2. Joung KW, Yang KH, Shin WJ, et al. Anesthetic consideration for neurointerventional procedures. Neurointervention. 2014;9(2):72-7

3. Lee CZ. Anesthesia for interventional nauroradiology. Rev Colomb Anestesiol. 2015;43:151-5 